\title{
The Analysis and Personnel Optimization of WeaveTech's Redundancy
}

\author{
Jin Wang \\ Institute of Information Technology of GUET, Guilin, Guangxi, China
}

\begin{abstract}
Redundancy" is a sensitive issue for each enterprise. However, many enterprises are forced to conduct redundancy due to business changes. As WeaveTech changes its main business sector from military clothing to civil highend performance clothes, the newly assigned management expects to cut the number of managers. The article aims to provide a guideline of redundancy for WeaveTech and evaluate it. Besides, several alternative methods other than redundancy are illustrated. Some thoughts gained through this case can be applied to other similar cases.
\end{abstract}

Keywords: redundancy; business change; alternative methods

\section{Introduction}

WeaveTech, formerly Johnson-Ware, is a clothing company specializing in production of military munitions, such as fire-resistant clothing, jackets, overalls and coveralls. Johnson-Ware was bought by CVX partners, a private equity firm in 2007. After that, WeaveTech gradually changes its strategic orientation, that is, from the early military key customer base to the high-end performance clothing market. With the significant changes, WeaveTech's new CEO expects to cut the number of managers by $20 \%$ to realize the enterprise transformation.

\section{The Context of WeaveTech}

The headquarter and other three plants of WeaveTech are located in New York. There are 315 managers and 1835 workers in its headquarter. WeaveTech firmly insists two main pillars of philosophy: customer-first and quality-supreme. Employees work with the belief that customers are partners and it is in their own interest to enhance the quality, growth, productivity, performance and profitability of the customer. Hence, the general trend of the company's operation steadily grows.

WeaveTech works in a dynamic context. There are three main reasons. Firstly, the business is influenced by the events. For example, the sales dramatically increased from 2001 to 2008 due to the wars in Iraq and Afghanistan. Secondly, the policies could affect the industry. As a case in point, Obama began unwinding the foreign policy approach in 2008. Hence, the number of military personnel and the demand and sales of military munitions were decreased. Finally, the fashion trend of clothing is difficult to predict and the technologies are continuously renewed.

Based on Ansoff's framework, WeaveTech applies the product development strategy in its business. To illustrate, the firm develops new products through its existing advanced technologies of military munitions, like water resistant and lightweight, to explore the market of performance clothing. It not only can help WeaveTech to extend the product range and share the existing market, but also could introduce the new products for firm's existing customers and attract them.

Copyright (C) 2020 by author(s) and Frontier Scientific Research Publishing Inc.

This work is licensed under the Creative Commons Attribution International License (CC BY 4.0).

$\mathrm{http} / / /$ creativecommons.org/licenses/by/4.0/ 


\section{Reasons for Redundancy}

Firstly, the business strategy of WeaveTech has been changed. The company would like to change the existing sales structure from $70 \%$ military and $30 \%$ security customers to the high-end performance clothing market, because the industry of outdoor apparel is the fastest-growing segment of the sports-apparel market. The data statistics from WeaveTech show that the retail growth of clothing is forecast to outperform total retail growth between 2017 and 2022, as the third fastest growing sector after health \& beauty and food \& grocery. The UK clothing market will grow by $16.6 \%$ over the next five years to $£ 51.2$ billion.

Secondly, CVX partners bought WeaveTech in 2007. However, CVX partners fell in the industry ranking of private equity firms in 2008, while CVX had dropped 12 in the annual ranking of the top 30 private equity firms in 2012. Hence, CVX pressures WeaveTech to improve its profitability level in both the short and long term so as to enhance CVX position in the rank of private equity firms.

Thirdly, the demand of traditional products is shrinking and the price sensitivity is rising. Moreover, the traditional customer base will continue to decline due to a variety of policies in the forecast, such as Obama's foreign policy approach of President Bush. It is worth mentioning that it definitely needs employees with different skill sets due to the change of product. Compared with costly training fee and the period of training, the organization prefers to choose redundancy and introduce the new talent instead of training existing employees.

Finally, the change of existing organization culture forces WeaveTech to lay off. The manager unit formerly focused on government contract compliance and business development with agencies in the Department of Defense. As the business changes, the company needs a new private-sector philosophy and organizational culture to support that philosophy. Dismissal and recruitment of new members can effectively break previous company culture of WeaveTech and build its own new culture to adapt the new market and industry.

\section{Processes for Redundancy}

"Good HR practices" show that three elements of redundant processes are often critical: consultation with employees, selection decisions and pre-post redundancy support for those made redundant as well as those who remain. Thus, following the three elements, there are several processes to recommend WeaveTech to layoff it $20 \%$ members of manager group.

Firstly, the organization should consult with its employees, which is emphasized in most accounts of downsizing in order to achieve mutual agreement. In WeaveTech company, the HR director could try to communicate with its workers to inquire whether employees are willing to leave voluntarily, especially for some workers whose careers have run into bottlenecks and hard to develop, or who meet family or physical problems and are difficult to keep working in WeaveTech. These employees may be the first to be laid off.

After consultation and voluntary redundancy, concerning the compulsory redundancy, WeaveTech can choose according to several conditions. First selection measure is based on assessment of skills and performance. For instance, there is a performance appraisal in WeaveTech, which includes eighteen assessment of category. Therefore, the manager could use the way to evaluate each workers and rank them according to their scores, and the bottom $20 \%$ of employees are eliminated. Secondly, the HR director can use sickness absences as criterion for redundancy. To illustrate, based on the EAP program of WeaveTech, there are 30 managers who have sought assistance due to cancers, diabetes and the whole range of other health concerns which health problems have severely impacted their works and working efficiency. Consequently, the HR director may provide these employees with early retirement or dismissal. Thirdly, WeaveTech heavily lays emphasis on issue of bureaucracy. Hence, the HR director could lay off $20 \%$ employees from D-Crop based 
on each member's performance as most members are selected by service veterans and possibly have nepotism. In the long run, retaining those employees probably has a negative impact on WeaveTech's development andis prone to the risk of bureaucracy.

Finally, WeaveTech should pay more attention to employee support. A wide variety of post-redundancy assistance must be offered to dismissal workers because it has a positive impact on the management of redundancy. There are two recommend methods in this report. The first is job-search help. HR director could try to find some similar positions or give some recommends for leaving staff. It not only can help leaving employees to find a job in a short time, but also can reduce employees dissatisfaction. Secondly, the organization needs to provide financial assistance or advice to departing workers because it could maintain employees' household expenses and minimize their financial crisis, such as loans, especially for the poor family.

In addition, it is worth mentioning that the company should consider providing some supports for remaining workers as well, like counselling psychology and chances to communicate with their managers, because after redundancy, the remaining employees are more likely to have low morale, increased stress levels, less productivity and less loyal with increased quit level.

\section{Difficulties and Effect of Redundancy}

Downsizing is often justified as a means to achieve longer-term strategy and improve its effectiveness, efficiency, productivity and competitiveness. However, it must be pointed out that redundancy is often badly managed, and brings many negative consequences. Concerning the difficulties of redundancy, in WeaveTech, the team of managers are mainly selected from service veterans and WeaveTech rarely fired employees, which is considered as a part of organization culture. As a result, during the process, employee resistance for redundancy must be a difficult and inevitable factor.

Regarding the harmful effects of redundancy, first and foremost, redundancy is likely to be associated with the creation of negative psychological and behavioral consequences for survivors, no matter how well it is managed. If WeaveTech fires $20 \%$ of managers suddenly, it will contradict its own commitment and lose trust of its employee, a number of issues will be created. To illustrate, when the remaining employees face the great change in the company, it will dramatically increase their sense of crisis and insecurity, and a serious of employees' behavioral reactions will be produced by the change, which seriously damages stability and benefits of WeaveTech, like absenteeism, intention to leave and resistance to change.

Secondly, the redundancy possibly has a negative effect on existing culture and decreases employees' moral and intrinsic motivation. As a case in point, WeaveTech rarely fired employees before. It made moral extremely high in the firm and could be seen as a part of company culture. However, $20 \%$ of the layoffs may make employees feel uncomfortable and present a great challenge for employees' moral and organizational culture. At the same time, it also has a damaging effect on workers' emotion, including anger, anxiety and guilty.

Thirdly, the sudden layoff probably brings about a lot of legal issues, such as unfair dismissal, which has an opposite effect on WeaveTech's reputation, and even needs to pay expensive compensation. For example, Employment Rights Act 1996 can be determined by a reasonable notice period for dismissal. In WeaveTech, the sudden $20 \%$ redundancy will probably face unfair dismissal because WeaveTech does not provide a reasonable period and notice for its employees.

Finally, WeaveTech may face the ethical problems and discrimination if its redundancy is based on data from EAP program. To illustrate, the data of EAP program is private data, but the company may open the data, and even uses it as evidence for redundancy. Consequently, this is a violates the code of ethics and possibly cause dissatisfaction among employees. 


\section{Alternative to Redundant Methods}

In order to avoid a range of harmful effects of redundancy, this report comes up with some alternatives for redundancy methods and evaluates them.

First and foremost, WeaveTech could use retraining to replace redundancy. Firstly, the method is suitable for WeaveTech's organization culture as the organization always lay heavily emphasis on its training, such as providing customized training and personal tutors for employees. Secondly, retraining could help the firm remain the current talents and help its workers to expand their skills. It is worth mentioning that retraining could not only prevent a series of dangerous influence of redundancy, but also dramatically improve WeaveTech's competitiveness and business flexibility. However, retraining also has some limitations. Firstly, the costs of retraining are relatively more expensive than direct recruitment, because in the manager team, a large number employees need to accept long-term training to exploit the new industry. Secondly, the result is unpredictable. To illustrate, in the manager group, the members' average age is over 48, which makes it difficult to predict whether they could successfully achieve the expected results after training and how to remain them in the further.

The second recommended alternative of redundancy is flexible working. The report of CIPD and KPMG illustrates that nearly a fifth of firms surveyed are making greater use of flexible working instead of redundancy. For example, city law firm Norton Rose provided alternatives to redundancy in 2009. Staffs were offered the option of working four-day weeks at $85 \%$ of their salary or taking a sabbatical of up to 12 weeks at $30 \%$ of their salary. WeaveTech can replace redundancy by adjusting employees' working hours. On the one hand, by exploring these options with staffs, the firm is able to retain more staffs, along with their knowledge, skills and contacts, and save the redundancy costs and the costs of recruiting and training new staffs. On the other hand, it could reduce the workload and provide flexibility for its employees. As a result, this means that a reasonable work schedule is particularly important, and those who work flexibly may feel that employers think their commitments are less strict.

\section{Conclusions and Recommendations}

With the development and expansion of business of WeaveTech, the redundancy is considered inevitable, but managers should seriously consider and evaluate the benefits and negative effects. The article suggests that HR directors should use voluntary redundancy at first to achieve mutual agreement in order to minimize the losses and harmful effects. After that, if the firm could apply a series of criteria to process compulsory redundancy, it should provide adequate supports to its employees, either unemployed or remained, to ensure the company to resume operations in the shortest time. Finally, reasonable measures must be taken to provide alternatives to compulsorily make people redundant, and the employer should seriously evaluate these alternative measures.

\section{Conflicts of Interest}

The author declares no conflicts of interest regarding the publication of this paper.

\section{References}

[1] Beer M. and Swiercz P. (2015). WeaveTech: High Performance Change. Harvard Business School.

[2] Cision (2017). The UK Clothing Market 2017-2022. http://www.prnewswire.com/news-release/the-uk-clothingmarket-2017-2022-300483862.html.

[3] Wolf J. F. and Goodsell C. T. (1993). International Review of Industrial and Organizational Psychology. Wiley, New York.

[4] Hart H. (2016). Flexible Working and Redundancy -- Two Sides of the Same Coin. https://www.mumandcareer.co.uk/resources/flexible-working-and-redundancy---two-sides-of-the-same-coin/. 
[5] Employment Rights Act (1996). 230(2).

[6] Martindale N. (2009). Redundancy: Top 10 Alternatives. https:// www.personneltoday.com/hr/redundancy-top-10alternatives/.

[7] Millmore M. (2007). Strategic Human Resource Management-Contemporary Issues. Edinburgh Gate, England.

[8] Wilkinson A., Redman T. and Dundon T. (2001). Contemporary Human Resource Management: Text and Cases. $15^{\text {th }}$ ed. Pearson Education, United Kingdom. 